\title{
Article
}

Subscriber access provided by ECU Libraries

\section{A\#-AMYLOID FIBRILS ARE SELF-TRIGGERED BY THE INTERFACIAL LIPID ENVIRONMENT AND LOW PEPTIDE CONTENT}

\author{
Alain Alvarez Bolaño, Benjamín Caruso, Pablo E.A. Rodriguez, Steffen B. Petersen, and Gerardo D. Fidelio
} Langmuir, Just Accepted Manuscript • DOI: 10.1021/acs.langmuir.0c00468 • Publication Date (Web): 18 Jun 2020

Downloaded from pubs.acs.org on June 20, 2020

\section{Just Accepted}

"Just Accepted" manuscripts have been peer-reviewed and accepted for publication. They are posted online prior to technical editing, formatting for publication and author proofing. The American Chemical Society provides "Just Accepted" as a service to the research community to expedite the dissemination of scientific material as soon as possible after acceptance. "Just Accepted" manuscripts appear in full in PDF format accompanied by an HTML abstract. "Just Accepted" manuscripts have been fully peer reviewed, but should not be considered the official version of record. They are citable by the Digital Object Identifier (DOI@). "Just Accepted" is an optional service offered to authors. Therefore, the "Just Accepted" Web site may not include all articles that will be published in the journal. After a manuscript is technically edited and formatted, it will be removed from the "Just Accepted" Web site and published as an ASAP article. Note that technical editing may introduce minor changes to the manuscript text and/or graphics which could affect content, and all legal disclaimers and ethical guidelines that apply to the journal pertain. ACS cannot be held responsible for errors or consequences arising from the use of information contained in these "Just Accepted" manuscripts. 


\title{
A $\beta$-AMYLOID FIBRILS ARE SELF-TRIGGERED BY THE INTERFACIAL LIPID ENVIRONMENT AND LOW PEPTIDE CONTENT
}

\author{
Alain Bolaño Alvarez ${ }^{1, \#}$, Benjamín Caruso ${ }^{3,4 \#}$, Pablo E. A. Rodríguez ${ }^{5}$, Steffen B. Petersen ${ }^{6}$ and Gerardo \\ D. Fidelio ${ }^{1,2 *}$ \\ ${ }^{1}$ Departamento de Química Biológica Ranwel Caputto, Facultad de Ciencias Químicas, Universidad Nacional de Córdoba, \\ Argentina. \\ ${ }^{2}$ Centro de Investigaciones en Química Biológica de Córdoba, CIQUIBIC, CONICET, Universidad Nacional de Córdoba, \\ Argentina. \\ ${ }^{3}$ Cátedra de Química Biológica, Departamento de Química, Facultad de Ciencias Exactas, Físicas y Naturales, Universidad \\ Nacional de Córdoba, Argentina. \\ ${ }^{4}$ Instituto de Investigaciones Biológicas y Tecnológicas (IIBYT), CONICET, Universidad Nacional de Córdoba. Córdoba, \\ Argentina. \\ ${ }^{5}$ Ministerio de Ciencia y Tecnología de la Provincia de Córdoba, Argentina. \\ ${ }^{6}$ Department of Health Science and Technology, Faculty of Medicine, Aalborg University, Denmark. \\ \#These authors have contributed equally to this work as co-first authors. \\ ${ }^{*}$ Corresponding author: gfidelio@unc.edu.ar
}

\begin{abstract}
We studied the surface properties of $A \beta(1-40)$ amyloid peptide mixed with POPC (liquid state) or DSPC (solid state) phospholipids by using nano-structured lipid/peptide films (Langmuir monolayers). Pure A $\beta(1-40)$ amyloid peptide forms insoluble monolayers without forming fibril-like structures. In a lipid environment (phospholipid/A $\beta(1-40)$ peptide mixtures), we observed that both miscibility and stability of the films depend on peptide content. At low $A \beta(1-40)$ amyloid peptide proportion (from $2.5 \%$ to $10 \%$ of peptide area proportion) we observed the formation of fibril-like structure when mixed only with POPC lipid. The stability acquired by these mixed films is within $20-35 \mathrm{mN} \cdot \mathrm{m}^{-1}$ compatible with the equivalent surface pressure postulated for natural biomembranes. Fibrils are clearly evidenced directly from the monolayers by using Brewster Angle Microscopy. The so-called nano-structured fibrils are Thioflavin T positive when observed with fluorescence microscopy. The amyloid fibril network at the surface was also evidenced by Atomic Force Microscopy when the films are transferred onto mica support. A $\beta(1-$ 40) amyloid mixed with the solid DSPC lipid showed an immiscible behavior in all peptide proportions without fibrils formation. We postulated that the amyloid fibrillogenesis at the membrane can be dynamically nano-self-triggered at the surface by the quality of the interfacial environment, i.e. the physical state of the water-lipid interface and the relative content of amyloid protein present at the interface.
\end{abstract}

\footnotetext{
Abbreviations: A $\beta(1-40)$, $\beta$ eta amyloid 1-40 residue peptide; AD, Alzheimer Disease; POPC, 1-palmitoyl2-oleoyl-phosphatidylcholine; DSPC, 1,2-disteraoyl-phosphatidylcholine; PAP, percentage of Peptide Area Proportion in the lipid:peptide mixed surface; ThT, Thioflavin T.
} 


\section{INTRODUCTION}

Alzheimer Disease (AD) is the most common neurodegenerative disease in older individuals. Although the major risk is the age, the pathogenesis and degenerative processes are not well known and it can begin undetectable a decade before the symptoms become noticeable. ${ }^{1}$ However, in postmortem tissue samples, $\mathrm{AD}$ is characterized by two neuropathological lesions found in the brain, neuritic plaques accompanied of an extracellular insoluble core of amyloid peptides (A $\beta$ peptides) and intracellular filamentous aggregates of phosphorylate tau proteins denominated neurofibrillary tangles. ${ }^{1-2}$

It is known that the $A \beta$ peptides (of 1-40 and 1-42 residues length) are generated from the proteolytic (mis)processing of the Amyloid Precursor Protein (APP) by two different modes: the nonamyloidogenic and the amyloidogenic pathways. ${ }^{1,3}$ In the non-amyloidogenic pathway, APP is sequentially cleaved by $\alpha$ - and $\gamma$-secretases and endocytosed resulting an endosomal production of nonamyloidogenic P3 peptide. The amyloidogenic pathway is characterized by the (over)production of insoluble and neurotoxic A $\beta$ fragments (1-40 and 1-42) from the cleavage of APP by $\beta$ - and $\gamma$-secretase, resulting in the formation of $A \beta$ oligomers which are the precursors of the aggregate plaques. ${ }^{4}$ This vision is known as the consensus beta amyloid hypothesis. ${ }^{1}$

The proteolytic process of APP to generate A $\beta$ peptides is necessary associated to the membrane environment, however the implication of the membrane lipids in the early events of pathological aggregates have been neglected or rather, it has been given a more passive role. In this connection, membrane raft (or its more accurately definition as transient lipid nanodomains) ${ }^{5}$ has been implicated in the $\mathrm{A} \beta$ accumulation and $\mathrm{AD} .^{6-8}$

POPC is a pivotal lipid in natural membranes due to its importance in the structure and function of cellular membranes. ${ }^{7}$ POPC is the most abundant phospholipid in brain compared to the rest of phospholipids. ${ }^{9}$ It has been reported that phospholipids level in brain decreases with age by almost $50 \%$ between age 40 to 100 years old. ${ }^{10}$ This apparent "physiological" change with age has induced to some authors to suggest that the decrease of phospholipid levels in brain could be related to $\mathrm{AD},{ }^{7}$ specifically POPC. ${ }^{11-12}$ Furthermore, from studies in CSF (cerebrospinal fluid), which is the most informative sample 
for monitoring the pathological processes in brain, has been suggested that an increase in POPC hydrolysis could be associate with AD. ${ }^{13}$

APP is a transmembrane protein, so the proper interaction with membrane phospholipids or a nonleakage processing of $A \beta$ peptides would contribute to the normal homeostasis in brain. According to $A \beta$ amyloid hypothesis, the non-physiological accumulation of $\mathrm{A} \beta$ peptides would trigger early oligomerization and neuronal injury and further dissemination of AD. ${ }^{1}$ So, taking into account that phospholipids provide an optimal environment to the membrane proteins function and contribute to the normal neuronal ionic homeostasis, many authors have focused their studies to the interaction of $A \beta$ peptides and derivatives with lipids using membrane model systems. Particularly, it has been reported the electrostatic interaction of 25-35 segment of $A \beta$ peptide with negatively charged phospholipid vesicles ${ }^{14}$ and the complete $A \beta(1-40)$ sequence with anionic lipid monolayers. ${ }^{15}$

Langmuir monolayers at the air-water interface is a proper technique to study the interfacial behavior of film forming peptides mixed with lipids. The potential of this approach to study the surface properties of $\mathrm{A} \beta$ amyloid peptides has been highlighted by Leblanc and coworkers. ${ }^{16}$ Langmuir monolayers allow to manipulate the lipid/peptide mole ratio, the amount of the percentage of peptide area proportion, the physical state of the lipid and the degree of lateral compactness in a confined environment, mimicking a biological membrane interface. A $\beta$ peptide (either 1-40 or 1-42) is part of the anchoring membrane domain of APP and is very hydrophobic. We have previously described that $A \beta(1-42)$ forms insoluble monolayers at air-water interface with a lateral stability of around $30 \mathrm{mN} \cdot \mathrm{m}^{-1}$ and a molecular area at maximal packing of around $2.5 \mathrm{~nm}^{2} /$ molecule. ${ }^{17}$ In this previous report, using giant unilamellar vesicles (GUVs), we described the strong interaction of $\mathrm{A} \beta(1-42)$ with GUVs provoking both $i$ ) the reduction of lateral membrane cohesive forces and ii) the breaking of transbilayer gradient causing a time-dependent release of small and large solutes loaded in the liposomes. ${ }^{17}$

More recently, we reported that pure A $\beta$ peptide, under the condition that had been proved to form stable and structured $\beta$-sheet monomolecular layers at air/water interface, presenting a peculiar high elastic shear modulus when compared to pure $\alpha$-helix lytic melittin peptide. ${ }^{18}$ A similar behavior was recently 
reported for the adsorption of the intrinsically disordered C-terminal of the Hendra virus nucleoprotein $\left(\mathrm{N}_{\mathrm{TAIL}}\right)$ to air/water interface. ${ }^{19}$

In the present work we show that $\mathrm{A} \beta(1-40)$ amyloid peptide forms a fibril like structure at a particular range of lipid/Aß peptide proportion when the mixed surface is dominated by POPC. Certainly, between 2.5 and $10 \%$ of A $\beta$ amyloid Peptide Area Proportion (PAP) the fibril-like structure can be evidenced by Thioflavin T (ThT) fluorescence, Brewster Angle Microscopy (BAM) and Atomic Force Microscopy (AFM). The surface peptide area contribution relative to lipid, PAP, is important when the film forming molecules have very dissimilar individual molecular areas. ${ }^{20}$ Percentage of peptide area proportion can be calculated from the individual data according to: $\mathrm{PAP}=100\left(\left(n_{P} A_{P} /\left(n_{L} A_{L}+n_{P} A_{P}\right)\right)\right.$, where $n_{P}$ and $n_{L}$ are the moles of peptide and lipid in the mixture and $A_{P}$ and $A_{L}$ are the individual molecular areas of peptide and lipid, respectively. In addition, we also demonstrate that the fibrillogenesis effect induced by POPC at air-water interface is sensitive to physical state of phospholipid since the mixing behavior of $\mathrm{A} \beta$ peptide with DSPC, a lipid in solid state at room temperature (liquid condensed state in Langmuir monolayers words), behaves lateral immiscibility with no fibrils formation. The interfacial conditions in which the more natural POPC/A $\beta$ amyloid peptide mixture induce fibril like structures strongly depends on lipid/peptide proportion and it was observable only at low A $\beta$ amyloid proportion.

\section{RESULTS}

\section{Surface properties of A $\beta(1-40)$ in POPC or DSPC mixed films. $\pi$-Area isotherms and BAM analysis.}

The formation of a insoluble monolayer of many amphiphilic molecules can occur at air-water interface. ${ }^{21}$ By using a Langmuir trough, the compression of the insoluble monolayer is possible by imposing a movable barrier to generate surface pressure $(\pi)$-Area isotherms. Surface pressure defined as $\pi=\gamma_{0}-\gamma$ is the difference between the pure interfacial tension of water $\left(\gamma_{0}\right)$ and the surface tension of amphiphilic covered surface $(\gamma)$ depends on lateral packing, surface concentration and miscibility behavior of the components. ${ }^{21-24}$ A modern view of the origin of the $\pi$ value has been related to the changes of surface water activity at the interfacial region. ${ }^{25}$ 
According to our previous results, both $A \beta(1-42)$ or the two residues shorter $A \beta(1-40)$ have almost identical behavior in monolayers at air water interface. ${ }^{17-18}$ Pure $\mathrm{A} \beta$ peptides form insoluble monolayers at air-water interface with a maximal lateral stability of around $30 \mathrm{mN} . \mathrm{m}^{-1}$ and a limiting molecular area at maximal packing of around $2.5 \mathrm{~nm}^{2} /$ molecule (Fig. 1). The maximal stability of pure $\mathrm{A} \beta$ peptide monolayers is in between the stability acquired by the lytic amphiphilic melittin peptide $\left(\sim 19 \mathrm{mN} \cdot \mathrm{m}^{-1}\right)$ or pure phospholipids in liquid-expanded state $\left(\sim 40 \mathrm{mN} \cdot \mathrm{m}^{-1}\right) .{ }^{26}$ Pure $\mathrm{A} \beta(1-40)$ peptide films behave as a typical solid films with a very peculiar high rheological property. ${ }^{18}$ The BAM imaging of pure A $\beta(1-40)$ film is homogeneous with neither observable fibril like structure (Fig 1), as we have observed previously, ${ }^{18}$ nor sensitivity to ThT fluorescent probe (see below and Fig. 4).

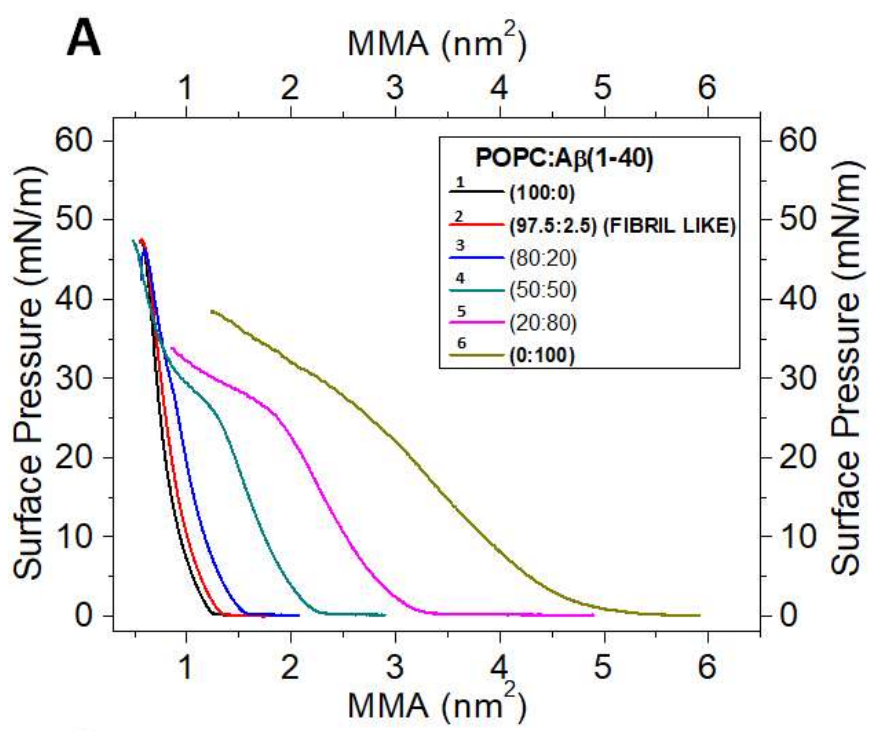

B
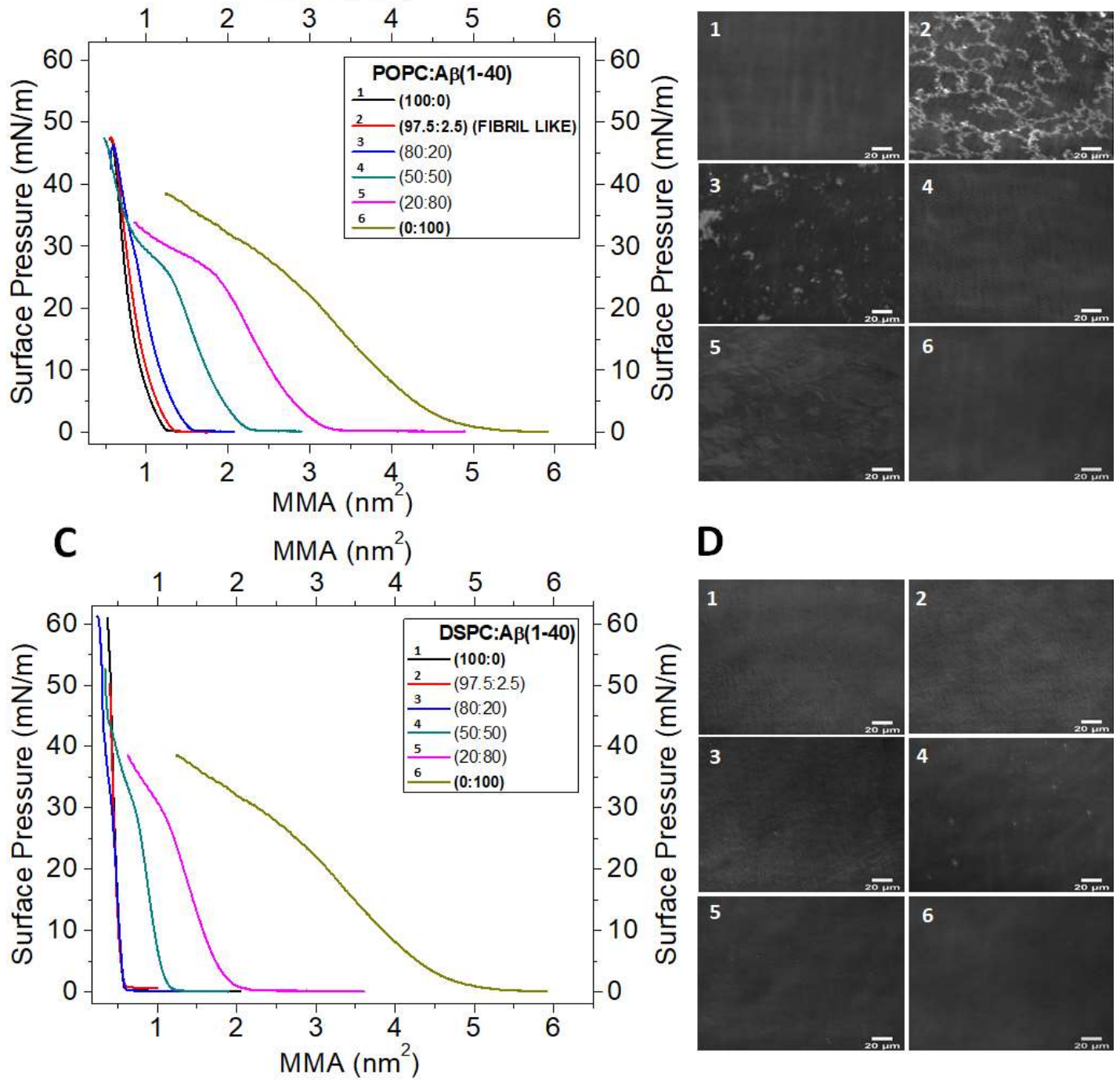

D

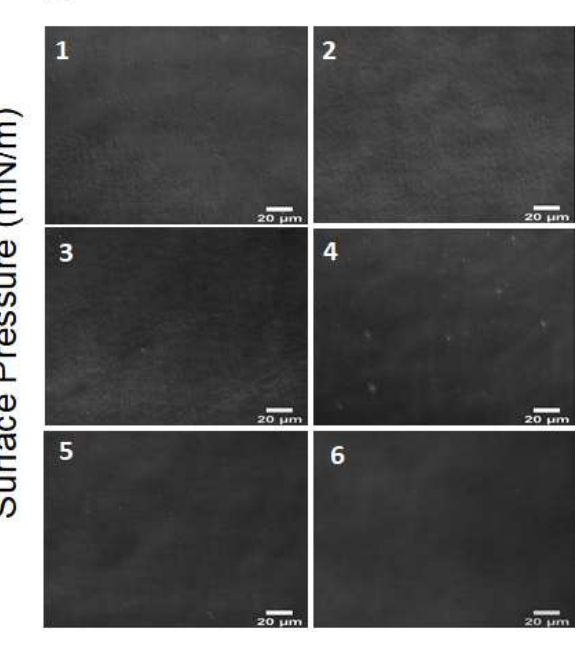


Figure 1: Surface behaviour of $\mathbf{A \beta ( 1 - 4 0 )}$ peptide in mixed films. $\pi$-Area isotherms for (A) POPC-peptide or (C) DSPCpeptide mixtures and their respective BAM images (B) and (D) obtained at $10 \mathrm{mN} \cdot \mathrm{m}^{-1}$ in pure films or the mixture at the indicate lipid-amyloid percentage of peptide area proportion, PAP, (showed in the insert). The corresponding lipid:peptide mole fraction proportion for POPC:A $\beta(1-40)$ peptide for each isotherm was 1:0; 0.995:0.005; 0.952:0.047; 0.835:0.164; 0.558:0.441; $0: 1$. The corresponding lipid:peptide mole fraction proportion for DSPC:A $\beta(1-40)$ peptide for each isotherm was $1: 0 ; 0.997: 0.003 ; 0.971: 0.029 ; 0.892: 0.108 ; 0.674: 0.326 ; 0: 1$. At the POPC:A $\beta(1-40)$ mixture at 97.5:2.5 of PAP, the mixed film shows fibril-like structures (picture B-2) but the picture B-3 at 80:20 of PAP shows domains indicative of a different immiscibility behavior. Conversely, DSPC:A $\beta(1-40)$ mixtures at the same PAP proportions showed a different behavior (solid-solid immiscibility at all proportions, see the text). MMA: mean molecular areas of the mixed film were calculated as indicated in Experimental Section. The solid bar in the pictures represents $20 \mu \mathrm{m}$. A greater detail of the profile of $\pi$-A isotherms at low $A \beta(1-40)$ peptide content can be seen in Fig. S1.

We studied the surface mixing behavior of $A \beta(1-40)$ peptide with two phospholipids differing in their physical state at room temperature $\left(23^{\circ} \mathrm{C}\right)$. POPC has a completed liquid-expanded isotherm (Fig. 1A and Fig. S1). For the contrary, DSPC behaves as completely liquid-condensed isotherm at air/ $\mathrm{NaCl}$ $145 \mathrm{mM}$ subphase (Fig. 1C). An expanded figure on the x-axis to appreciate the isotherms in greater detail can be seen in Fig. S1 of Supplemental Information. To observe the influence of A $\beta$ peptide proportions in the mixture, we have used the following percent of Peptide Area Proportion (PAP): 97.5:2.5, 80:20, 50:50 and 20:80 of calculated as indicated above. To each value of PAP it corresponds a relative high mole fraction of POPC of $0.995 ; 0.952 ; 0.835 ; 0.558$, respectively (see Fig 1 ), due to the dissimilar molecular areas of the phospholipid compared with $A \beta(1-40)$ peptide. This is an important concept to take into account when mixing protein with lipids in Langmuir monolayers since they have great differences in the individual molecular areas; so a small mole fraction of any protein would correspond with a significant high total surface area occupied and, therefore, influencing the surface behavior of the mixture. ${ }^{20,26} \mathrm{~A} \beta(1-40)$ peptide mixed with the more solid DSPC phospholipid did not form fibril-like structure regardless of amyloid proportion. All the DSPC/amyloid mixtures behave as a solid-solid immiscibility with a first collapsing point similar to the value found for pure peptide (Fig, 1C, Fig 2 upper part and Fig. S1). The BAM pattern is compatible with solid phases without the formation of fibril-like structures. Fig $1 \mathrm{D}$ shows the $\pi$-A isotherms with the corresponding BAM images taken at 10 $\mathrm{mN} \cdot \mathrm{m}^{-1}$. At this lateral packing $\left(10 \mathrm{mN} \cdot \mathrm{m}^{-1}\right)$ the molecular area of $\mathrm{A} \beta(1-40)$ peptide of $3.92 \mathrm{~nm}^{2} \cdot \mathrm{molec}^{-1}$ (see Fig. 1) is higher than POPC $\left(0.94 \mathrm{~nm}^{2}\right)$ or DSPC $\left(0.52 \mathrm{~nm}^{2} . \mathrm{molec}^{-1}\right)$ thus, the mixed isotherms move towards greater molecular area values as the mole fraction of the amyloid peptide increases. 
The miscibility behavior with POPC is completely different. Mixed films of POPC:amyloid at 97.5:2.5 of PAP form an observable fibril-like structure (see Fig 1B, picture 2). Is important to note that at this proportion of PAP corresponds to a mole fraction of amyloid of 0.005 . We found this particular behavior with POPC at around this proportion. At this proportion the fibril-like structures are ThT positive (see and Fig 4). If the A $\beta(1-40)$ peptide proportion is increased more than $10 \%$ of PAP, corresponding to a peptide mole fraction of 0.021 , the fibril-like structures disappear and the ThT analysis becomes negative.

In mixed interfaces, the profile and behavior of $\pi$-Area isotherms allow us to experimentally build the phase diagram, ${ }^{27}$ see Fig. 2 . For DSPC:A $\beta$ peptide mixtures we found a typical solid-solid immiscibility. For this mixtures, the first collapsing point (first discontinuity in the $\pi$-Area isotherm, see Fig S2) is compatible with the protein phase and appears independent of the $A \beta(1-40)$ proportion, indicating solid-solid immiscibility ${ }^{21}$ at all peptide proportions (see Fig. 2 upper part).

For POPC:A $\beta$ peptide mixtures the miscibility behavior is more complex. At low A $\beta$ peptide mixtures (less than $10 \%$ of PAP or less than 0.03 of peptide mole fraction), the surface miscibility analysis suggests that the mixed POPC:A $\beta(1-40)$ films are miscible where the first collapsing point has an intermediate value in between the pure POPC or pure $\mathrm{A} \beta(1-40)$ peptide, with the concomitant formation of fibril-like structures observable by AFM (Fig. 1) and becomes ThT positive (Fig. 4). At greater A $\beta$ peptide proportion the miscibility behavior is almost ideal (Fig. 2 lower part).

The complexity of POPC:A $\beta$ peptide mixed behaviour can be appreciated from a more perusal BAM analysis. In other to ascertain the complexity of BAM analysis, we have determined the variation of BAM reflectivity upon film compression for POPC:A $\beta(1-40)$ mixtures. From the analysis, we were able to discriminate into three well defined patterns of reflectivity (see Fig. 3A highlighted with different colours). The high reflectivity values corresponds to pure $A \beta(1-40)$ peptide (pure peptide phase); low reflectivity values are similar to those found for pure POPC lipid (pure lipid phase) and, the third ones with intermediate reflectivity values attributable to a more protein enriched mixed phase including the fibril phase formation. POPC:A $\beta(1-40)$ at PAP proportion of 97.5:2.5, 80:20 and 20:80, the mixed films 
domains have intermediate reflectivity values (Fig. 3A). At both extremes, pure POPC or pure A $\beta(1-40)$

peptide films we have the limits of low and high reflectivity values, respectively. At 97.5:2.5 of PAP

(corresponding to a $\mathrm{A} \beta$ peptide mole fraction of 0.005 ) we found the typical fibril-like phase (Fig. 3B).
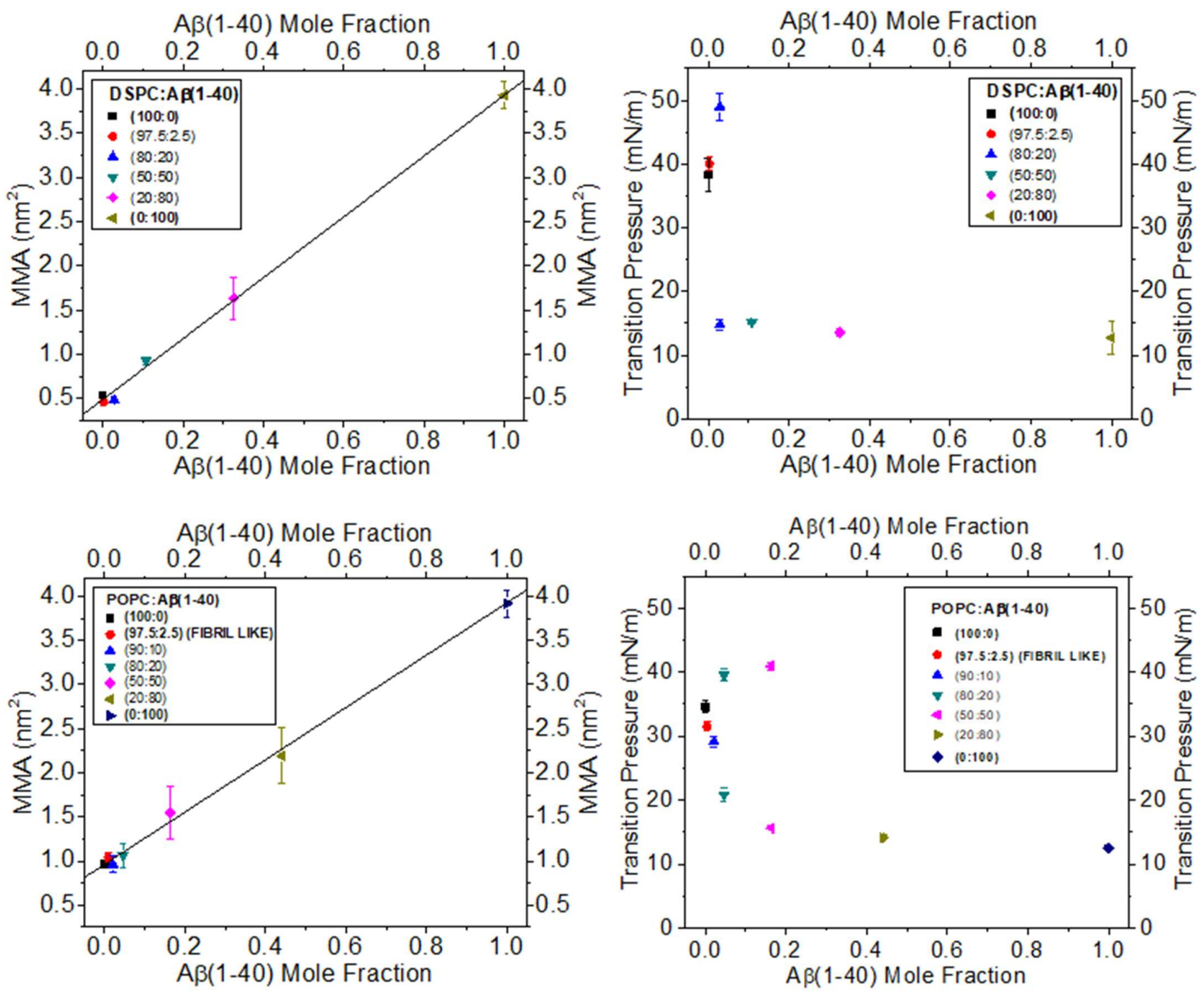

Figure 2: Phospholipid:Aß(1-40) peptide miscibility phase diagram. Upper part: Phase diagram for DSPC:A $\beta(1-40)$ mixtures showing lateral immiscibility; left: mean molecular area vs mole fraction taken at $10 \mathrm{mN} . \mathrm{m}^{-1}$; right: first collapsing point in the $\pi$-Area isotherm. Lower part: Phase diagram for POPC:A $\beta(1-40)$ mixtures. left: mean molecular area vs. mole fraction taken at $10 \mathrm{mN} . \mathrm{m}^{-1}$; right: first collapsing point in the $\pi$-Area isotherm. The POPC:A $\beta(1-40)$ mixture has a complex miscibility behavior. Here we included an additional mixture $(90: 10)$ for a more complete description of mixing analysis. At POPC:A $\beta(1-40)$ mixed at (80:20) and (50:50) of PAP proportions behave lateral immiscibility. At lower A $\beta$ peptide proportion, the mixture behaves partial miscibility with the first collapsing point corresponds to protein enriched phase at a value above of that observed for pure amyloid (see Fig. 1 and Fig S1 for more details). Transition Pressure means the first discontinuity point calculated by second derivative of $\pi$-Area isotherm with respect to area. At intermediate peptide proportions we also observed a second transition pressure (collapsing point) related to the lipid-enriched phase (see Experimental section and Fig. S2). The straight black line in the left upper and lower part corresponds to the ideal molecular area (see Experimental section for more details). 

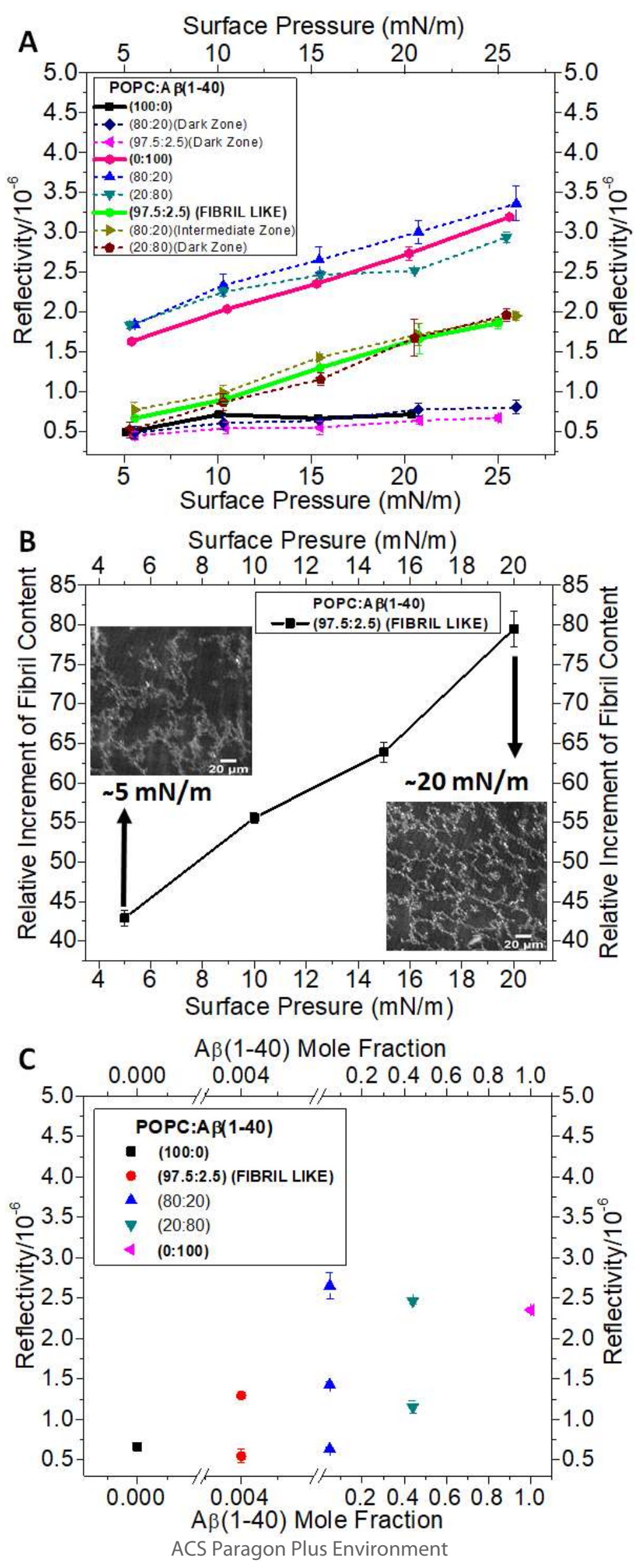
Figure 3: BAM reflectivity analysis of mixed POPC:Aß(1-40) films. A: reflectivity values indicating the three distinguishable (and measurable) regions in BAM intensity from POPC:A $\beta(1-40)$ mixtures indicated with three different colors. Low values are close to pure POPC lipid (black); high reflectivity range values were similar to pure A $\beta(1-40)$ peptide (magenta) and intermediate reflectivity values correspond to fibril-like structures or protein enriched phases (light green). Insert describes the origin of the data indicating the PAP and the zone where the plotted values of reflectivity were taken. B: Relativity percentage increment of fibril-like formation as surface pressure increases at POPC:A $\beta(1-40)$ at $97.5: 2.5$ of PAP proportion; left insert: picture of fibril-like structures taken at low surface pressure, right insert: picture of fibril-like structures taken at high surface pressure. The percentage of relative fibril content in B was calculated for each photograph in digital form between an all-black state $(0 \%)$ and all bright in the gray scale $(100 \%)$ by using Fiji Image J software. C: BAM reflectivity values of pure POPC, pure $\mathrm{A} \beta(1-40)$ and at different POPC:A $\beta(1-40)$ proportions taken at the distinguishable domains at $15 \mathrm{mN} \cdot \mathrm{m}^{-1}$.

At this particular proportion, fibril structure growths as the surface pressure increases until almost duplicate the relative domains of fibril-like structures (see Fig. 3B). As A $\beta$ peptide proportion increases up to a PAP greater than $20 \%$ (above 0.1 of amyloid mole fraction), the mixed films appear with intermediate reflectivity values but no fibril-like structures were detected and, we also observed pure protein domains with high reflectivity. At above $50 \%$ of PAP ( 0.047 of amyloid mole fraction), the mixed surface behaves as pure protein (Fig. 3C).

Thioflavin T and AFM analysis of mixed POPC:Aß(1-40) films. It is well known the ThT probe has particular fluorescent properties when interact with fibril-like amyloids in solution ${ }^{28-29}$ or at surfaces by using total internal reflection fluorescence microscopy (TIRFM). ${ }^{30}$ We have adapted a method to transfer the mixed monolayer to mica support followed of an incubation with a drop of ThT for 10 minutes and the direct observation by FM (see Experimental section). We have routinely used this methodology to check if the fibril-like structures observed by BAM of POPC:A $\beta(1-40)$ films at 97.5:2.5 of PAP are ThT positive. Transferred monolayers, in this proportion, show a fluorescence intensity pattern resembling fibril-like structure (Fig. 4B). We have checked that transferred monolayers of either pure $A \beta(1-40)$ or POPC were ThT negative, (Fig. 4B). We have quantified the fluorescence intensity of ThT positive pattern of fibril-like structure induce by POPC in comparison with the using negative controls (pure lipid and pure peptide, see Fig 4A). We have used fibrils of $\alpha$-synuclein formed in bulk condition as positive control to check the ThT interaction in a similar condition to that we used in transferred films (see Fig. 4B). 

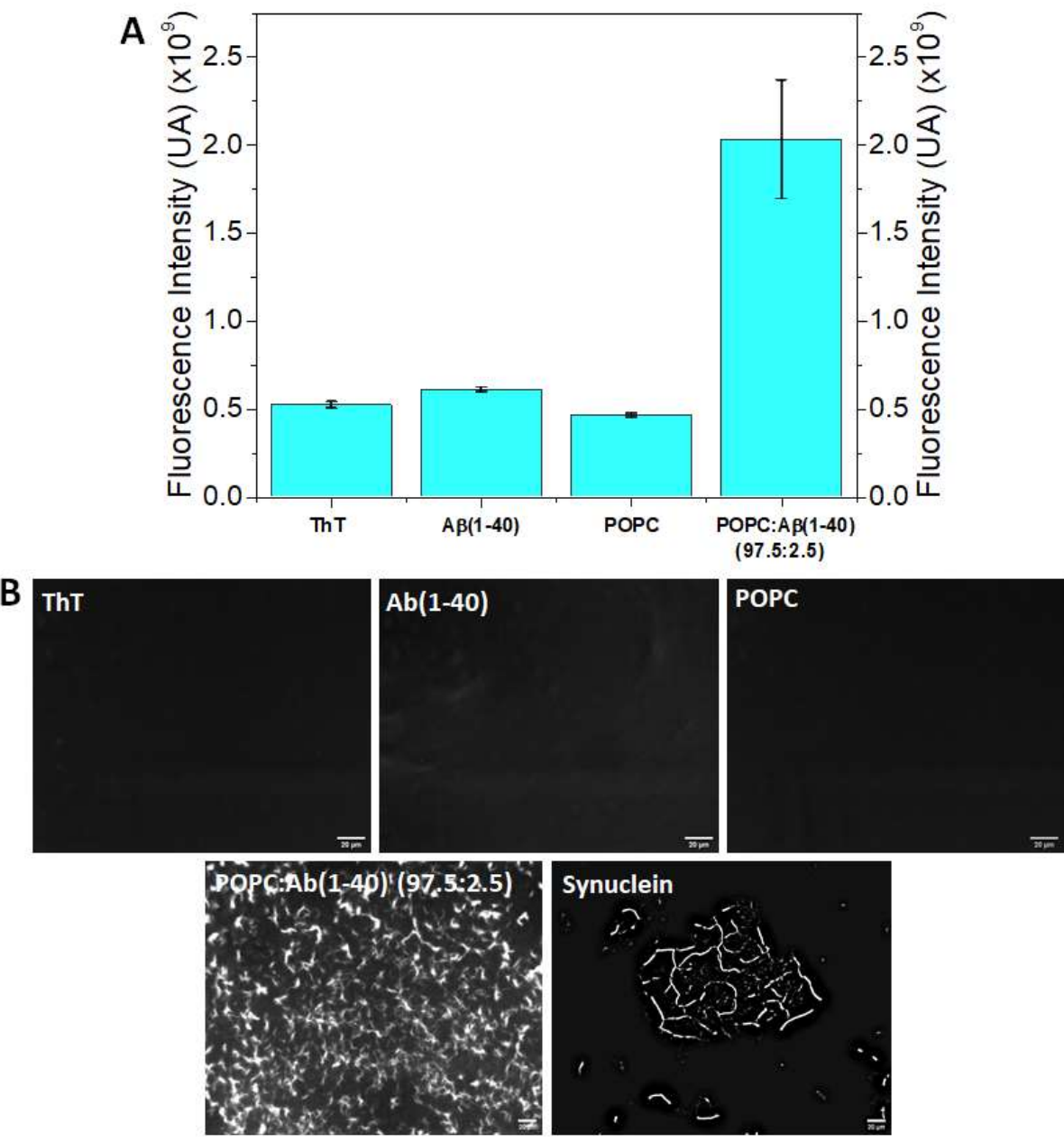

C

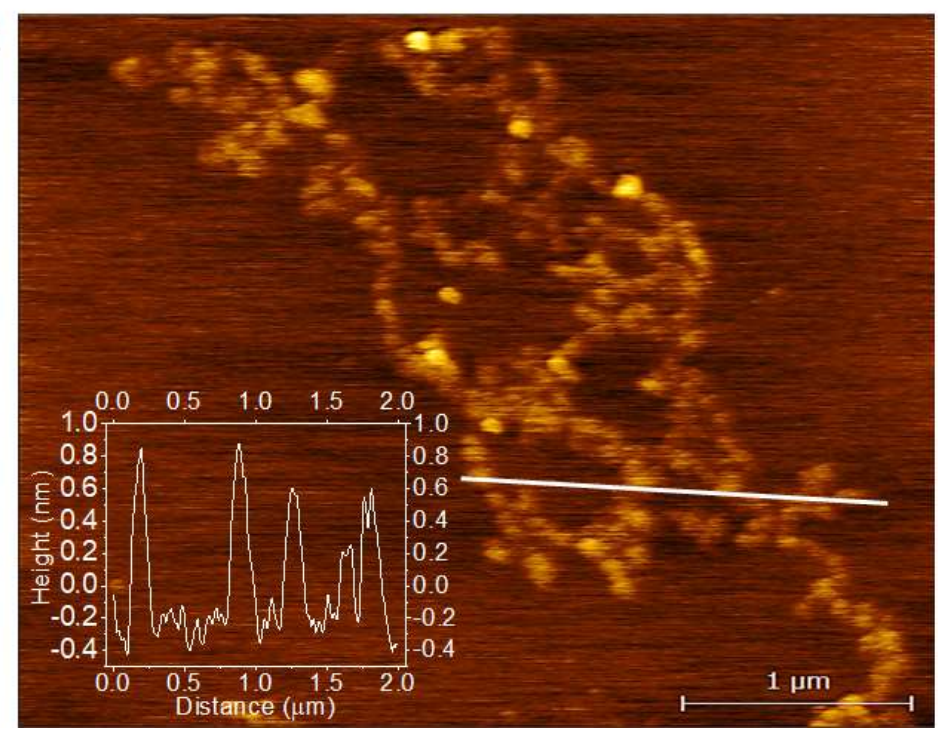

Figure 4: Thioflavin $T$ confirmation and AFM observation of amyloid $A \beta(1-40)$ fibrils induce by POPC at air-water interface. A: Fluorescence intensity values of transferred films from Langmuir trough (compressed to $20 \mathrm{mN} . \mathrm{m}^{-1}$ ) to solid support after ThT incubation. ThT controls: transferred pure A $\beta(1-40)$ peptide film, transferred pure POPC film; it is shown the average intensity of all fluorescence signal without imaging processing. B: Fluorescence images of negative controls and the fibril-like structure of POPC:A $\beta(1-40)$ mixed at 97.5:2.5 of PAP compressed up to $20 \mathrm{mN}^{-1}$ and then transferred to mica support. Positive control of $\alpha$-synuclein formed in bulk condition and transferred to solid support and incubated with ThT for FM observation. In the lower right corner, the white bar represents $20 \mu \mathrm{m}$. C: AFM topography imaging from mixed

POPC:A $\beta(1-40)$ at $97.5: 2.5$ of PAP proportion, compressed up to $20 \mathrm{mN} \cdot \mathrm{m}^{-1}$ then transferred to mica support; in the insert it is shown the periodicity of the fibril-like structure along of $2 \mu \mathrm{m}$ length (see big white bar). It is worth to note that the image of AFM is $4 \times 4 \mu \mathrm{m}$ whereas the BAM images is $200 \times 250 \mu \mathrm{m}$. (see Experimental Section for more details). 


\section{DISCUSSION}

Any hypothesis about the intimate molecular mechanism of amyloid formation in AD should be based on physiological conditions. Co-solvent effect, higher temperature or long-period of shaken, or combinations of some of them, are no normal constrains to trigger amyloid formation in brain. Most of authors converged that the (mis)processing and accumulation of $\mathrm{A} \beta$ peptides is initiated at the membrane environment. ${ }^{1}$ Recently it has been highlighted the strong interrelationship between lipids and amyloid formation by either the membrane as promoter of amyloid aggregation or self-assembled forming coaggregates with lipids that may disturb cell homeostasis. ${ }^{31}$ Both $\mathrm{A} \beta$ peptides, (1-40) and (1-42) are strongly hydrophobic and they correspond to the transmembrane segment of the APP protein. ${ }^{1}$ Both A $\beta$ peptides are able to form insoluble and stable monomolecular layers at air/water interface as membrane lipids do, with a relative high lateral stability. ${ }^{17,18}$ Previously, we also demonstrated that $\mathrm{A} \beta$ peptide is able to puncture bilayer membranes when the amyloid peptide is externally added to giant liposomes (GUVs). ${ }^{17}$ However, in this previous report we advanced that the lipid/A $\beta$ peptides miscibility was complex with a great tendency of lateral immiscibility behaviour. ${ }^{17}$ It is recognized that $A \beta$ amyloid peptides form $\beta$-sheet structure at the air/water interface. ${ }^{32-34}$ Depending on the experimental system used, Jiang and co-workers suggested that the structuring in $\beta$-sheet conformation may obey a certain pathway with distinguishable intermediates either at air/water interface: unordered monomer $_{(\text {bulk })} \rightarrow \alpha$-helix (sublayer) $\rightarrow \beta$-sheet (interface) $^{35}$ or in bulk conditions: amorphous $\operatorname{monomer}_{(\text {bulk })} \rightarrow$ colloid-like aggregates $(\text { bulk })_{\rightarrow}$ ordered $\beta$-sheet $\operatorname{oligomers}_{(\text {bulk })} \rightarrow$ fibrils $_{(\text {bulk })}{ }^{36}$

The A $\beta$ peptide/lipid miscibility in Langmuir monolayers did not follow the rule similar to others very hydrophobic $\beta$-sheet peptides. Indeed, very hydrophobic signal sequences peptides mix quite well with lipids regardless of lipid phase. ${ }^{37}$ Another characteristic of pure $A \beta$ amyloid peptide monolayers is its high rheological shear stress at the surface behaving as a two-dimensional solid network with a very low interfacial diffusion coefficient $\left(D \sim 0.005 \mu \mathrm{m}^{2} . \mathrm{s}^{-1}\right)$ similar or lower than liquid-condensed lipids. ${ }^{18}$ In the present report, we confirm our previous study that pure A $\beta$ amyloid peptide monolayers in this solid network did not form fibril-like structures ${ }^{18}$ nor they were sensitive to ThT probe (Fig 4). The presence of 
non-solvated liquid-condensed DSPC (a double saturated acyl chain phospholipid that at monolayers working temperature $\left(23^{\circ} \mathrm{C}\right)$ is below its critical transition temperature $\left(54.9^{\circ} \mathrm{C}\right)^{38}$ do not promote fibrillation keeping the solid network of $A \beta$ amyloid peptide and shows a solid-solid immiscible behaviour at all DSPC/A $\beta$ peptide proportion (Fig. 1). POPC is the main phospholipid constituent of membrane lipids in brain $^{7,9}$ with a fully liquid-expanded character at air/water interface ${ }^{39}$ and a critical transition temperature of $-3.7^{\circ} \mathrm{C} .{ }^{40}$ The introduction of POPC, a more physiological fluid lipid partner at the interface, acts as an inductor of fibril-like structures (see Fig. 1B and Fig. 3B). This particular and well characterized behavior is only observed at 2.5-10\% of peptide area proportion (PAP), a small range of A $\beta$ peptide proportion equivalent to $0.005-0.01$ of $A \beta(1-40)$ mole fraction in the mixture (Fig. 1B). The extent of fibrils formation was surface pressure dependent reaching an important and well defined non-covalent network at 20-30 mN.m ${ }^{-1}$ (Fig. 3B), a lateral pressure equivalent to bilayer and compatible with membranes. ${ }^{41}$ It is important to note that, in our experimental conditions, the fibril-like structures formed as a consequence of the interfacial conditions of peptide proportion, type of lipid and packing are ThT positive, (see Fig. 4B). It is widely accepted the particular reactivity of the fluorescent probe ThT with fibrils is one of the requirements that an aggregate must meet to be considered amyloid. ${ }^{29}$ In our experimental condition, the ThT positive amyloid fibrillogenesis only requires 2-5 minutes of spreading over a physiological saline subphase $\left(\mathrm{NaCl} 145 \mathrm{mM}\right.$ at $\left.23^{\circ} \mathrm{C}\right)$, mixed with a normal membrane phospholipid constituent and compressed to an equivalent membrane surface pressure. So, it was not necessary any extreme condition nor artificial co-solvent, high temperature, strong agitation or long period of incubation time for triggering irreversible amyloid fibrillation. It was previously reported that the presence of lipid free air/water interface accelerates the formation of amyloids either in $A \beta$ or in $\alpha$ synuclein peptides. ${ }^{42,43}$ Thus, the required conditions of high bulk concentration, agitation or long period of incubation time are quite different to those assayed by us. Our approach introduces a more realistic membrane model system with only the presence of a common and natural phospholipid constituent of membranes. 
From adsorption experiments, it has been reported that $A \beta(1-40)$ peptide interacts with the negatively charged polar head groups of POPG/POPC monolayers throughout electrostatic interactions, but with no further penetration into the lipid interface. The interpretation was the charged surface is acting as local seeding and the beta sheet or $\alpha$-helix content depends on the lipid/peptide mole ratio. ${ }^{44}$ Furthermore, substances that inhibited the state of membrane charges inhibited the toxicity of $A \beta(1-40)$ peptide. ${ }^{45}$ However, the experimental conditions assayed were far to "mimic" a physiological membrane environment since a low ionic strength and a high POPG/POPC ratios were employed. However, these results are keeping with ours since the authors remarked that $A \beta(1-40)$ peptide toxicity is mediated by nonspecific physicochemical interactions at the membrane interface. Therefore, all the data would converge to the concept of highlighting that it is possible that a given particular condition of the membrane has a more active and harmful role in inducing toxic beta amyloid fibrillogenesis.

In our hands, even that $\mathrm{A} \beta$ peptides forms insoluble and reproducible monolayers ${ }^{17-18}$ they do not get along with phospholipids. As we have shown, mixed with the solid DSPC A $\beta(1-40)$ peptide behaves immiscibility at all lipid/peptide proportions. This solid-solid lipid/peptide immiscibility in monolayers may be attributable to the strong $\beta$-sheet network of $A \beta$ peptide at the interface keeping with a low interfacial solvation and high shear rheology. ${ }^{18}$ Here, we demonstrated that this strong $\beta$-sheet network of pure A $\beta$ peptide at the interface is ThT negative and does not form fibril-like structure searched either by BAM or AFM. The interfacial protein concentration in a monolayer at lateral packing compatible with biomembranes $\left(20-30 \mathrm{mN} \cdot \mathrm{m}^{-1}\right)$ is surprisingly high. Taken into account that the molecular area of A $\beta(1-40)$ peptide at $25 \mathrm{mN} \cdot \mathrm{m}^{-1}$ is about $3 \mathrm{~nm}^{2}$ and, assuming an interfacial thickness of around $2 \mathrm{~nm}$ (taken into account the average thickness of AFM image, see Fig. 4) it gives a mean surface molecular volume of $6.000 \mathrm{~nm}^{3}$, the real protein surface concentration of a pure Aß peptide monolayer would reach the huge value of around $\mathbf{0 . 2 6} \mathrm{M}$. This surface concentration corresponds to a protein density of around $1.15{\mathrm{gr} . \mathrm{cm}^{-}}^{-}$ ${ }^{3}$, that is about the $80 \%$ of the reported value for protein density (around $1.35 \mathrm{gr.cm}^{-3}$ ). ${ }^{46}$ This is indicating that the local low solvation and high protein concentration of Aß(1-40) peptide at the interface is no enough to form amyloid fibrils. To trigger amyloid formation at the interface it is necessary the joint action of a phospholipid in the liquid state. We obtained partial miscibility when we introduced POPC as 
lipid partner in the mixed interface. At POPC:A $\beta(1-40)$ 97.5:2.5 of PAP (meaning that A $\beta$ peptide contributes with a $2.5 \%$ of the total area available of the mixed lipid/protein interface), we clearly see the ThT positive fibril-like structure. At this particular proportion, we observed a slight repulsive interactions according to the miscibility analysis (mean molecular area above to ideal mixed area, Fig. 2 lower part). This is keeping with the different BAM reflectivity found for fibril-like structure compared to pure protein, indicating that a change in $A \beta$ peptide conformation is induced by the liquid-expanded environment of POPC. It is noteworthy that this effect occurred when A $\beta$ peptide is surface diluted by the presence of a higher hydrated polar head group of POPC lipid when compared to more solid DSPC lipid. The level of interfacial hydration of phospholipids in different physical state in monolayers was already reported by Brewer et al. by using the properties of fluorescence relaxation of LAURDAN. ${ }^{41}$ For liquid expanded interfaces (above phase transition of the phospholipid) the value of LAURDAN GP is around -0.3 whereas for phospholipid in liquid condensed state is near to $0.5 .{ }^{41}$ If we combine these values with the interfacial water activity for liquid expanded phospholipid interfaces proposed by Damodaran, ${ }^{25}$ the equivalent water activity of our amyloid trigger condition would be around to 0.3 , whereas it is expected to be close to 0 for solid phospholipid interfaces. The highly non solvated interface of the liquid condensed phospholipid is not enough to break off the solid arrangement of the $A \beta$ peptide. A more hydrated phospholipid interface (in liquid state) triggers the $\mathrm{A} \beta$ peptide conformation to form fibril-like structures with both the typical ThT positive characteristic and a compatible AFM topography imaging. The hypothesis that the state of interfacial water activity may modulate the formation of fibrils-like structure in a liquid-expanded lipid environment is in keeping with the increment of fibrils structure upon film compression as it was shown in Fig. 3B. Indeed, for this type of liquid-expanded phospholipid interface LAURDAN GP goes from -0.55 to -0.3 with a change in the equivalent interfacial water activity from 0.9 to around 0.3 when the film is compressed from 2 to $20 \mathrm{mN} \cdot \mathrm{m}^{-1} \cdot{ }^{25,41}$ However, at this point it is necessary to be rigorous and it will be necessary to measure the degree of LAURDAN fluorescence in mixed A $\beta$-amyloid:lipid Langmuir films, that have not been done yet. We have obtained similar results with DMPC, a shorter saturated fatty acid phospholipid with an equivalent liquid-expanded property than POPC (data no shown), indicating that the physical state of the phospholipid is critic for $A \beta$ peptide fibrillation. In keeping with these data, it was 
reported a greater binding affinity of $A \beta(1-42)$ peptide for liquid disordered $L_{d}$ membranes than for liquid ordered $\mathrm{L}_{\mathrm{o}}$ environment. ${ }^{47} \mathrm{We}$ try to model a $2 \mathrm{D}$ lipid/A $\beta$ peptide organization model in its fibril-like state in accordance with the obtained data (see Fig. 5). The fibril-like structures at the interface shown intermediate values in BAM reflectivity which it is associate to the refractive index changes on the monolayer. These intermediate values of BAM reflectivity are in between the pure POPC (low values) and high values of the solid arrangement of pure $A \beta$ peptide (see Fig 3).
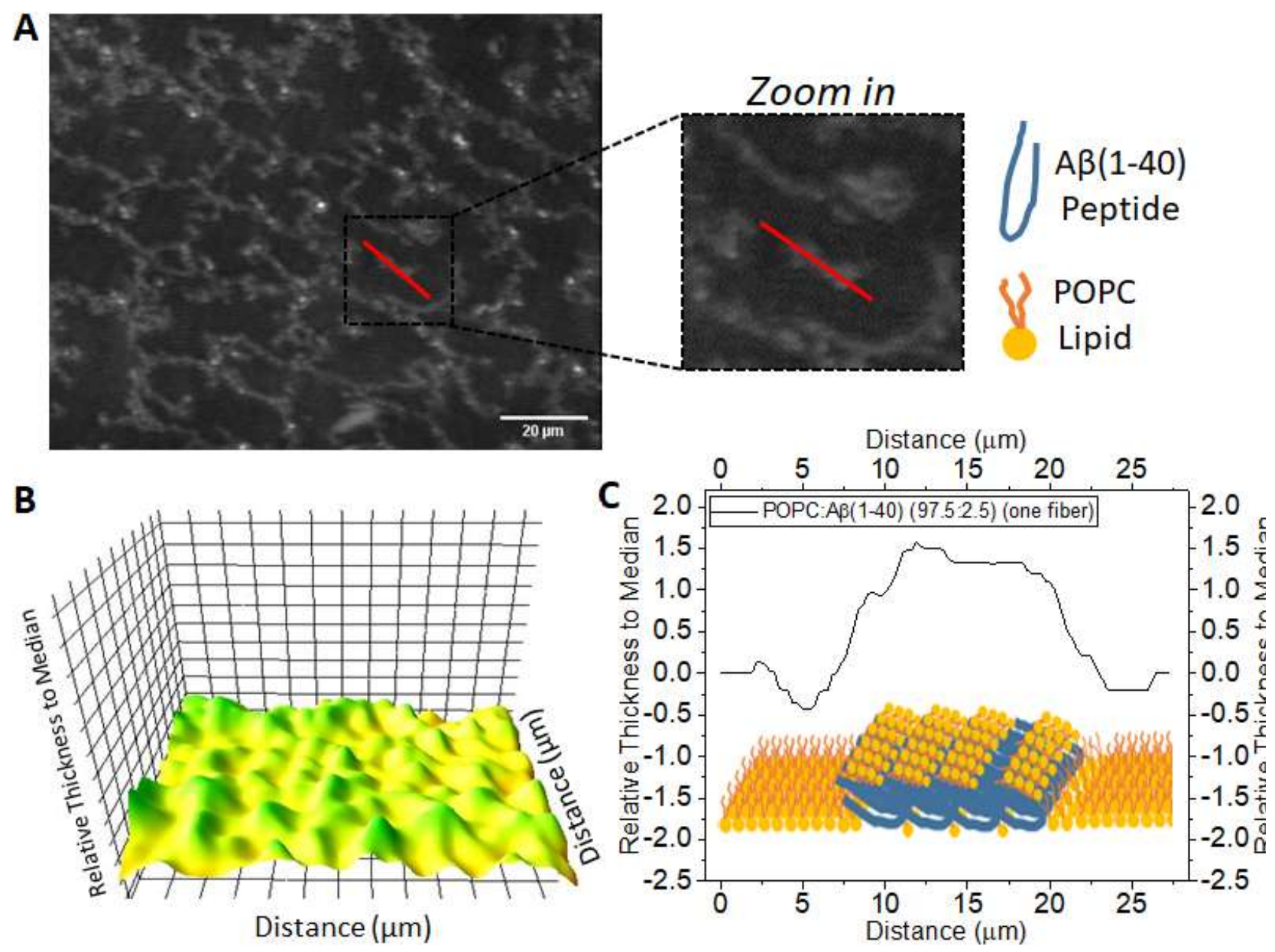

Figure 5: Modelling the fibril-like structure formed by Aß(1-40) peptide imposed by POPC interfacial conditions. A: (Left Panel) BAM imaging obtained at POPC:A $\beta(1-40)$ (97.5:2.5 of PAP) showing the interconnected fibril-like structure (higher reflectivity) confining the more enriched POPC phase (lower reflectivity); (Right Panel) zoom in on the black dot-line square showing details, the transverse red line denotes the pass of the relative thickness plotted in 5C in black line. B: Three dimensional representation using FIJI program showing the relative thickness along the A imaging with false colours, the green colour is the maximum height whereas the yellow colour is the minimum. C: Cartoon view of a possible model of fibril-like structure formed by lipid-rich co-assemblies with $\mathrm{A} \beta(1-40)$ peptide in fibril structures keeping the relative thickness of the above zoom-in imaging (aprox. $12 \mu \mathrm{m}$ length $\mathrm{x} 0.2 \mu \mathrm{m}$ height). 
Probably the interfacial conditions imposed by the liquid hydrated POPC gives an adequate environment to promote the formation of fibril-like structures of $A \beta(1-40)$ peptide in which the lipid is taken part in the enriched fibril-like phase with a distinguishable intermediate collapsing point in the interface (see the value of collapsing point of this "intermediate phase" corresponding to the red point in Fig. 2 lower part right side, of $32 \mathrm{mN} \cdot \mathrm{m}^{-1}$ and the BAM picture 2 of Fig. 1B). This fibril-like phase has a lateral stability lower than pure POPC of around $40 \mathrm{mN} \cdot \mathrm{m}^{-1}$.

Is well known that the $\mathrm{A} \beta$ amyloid peptides affect the membrane integrity, ${ }^{17}$ however the intimate molecular mechanism of membrane disruption or fibril promotion at membranes is not clear yet. ${ }^{31}$ The presence of membranes leading to amyloid peptide aggregation has been proposed by others authors either for $\mathrm{A} \beta$ peptides ${ }^{48-49}$ or for $\alpha$-synuclein. ${ }^{50}$ By using Molecular Dynamics (MD) it was already postulated the importance of "surface quality" of membrane bilayers in A $\beta$ amyloid binding and fibrillation. ${ }^{47}$ The effective participation of phosphatidylcholine in the fibrillation process is supported by the fact that this lipid is found in amyloid fibril deposits in pathologic AD plaques or in Parkinson's disease. ${ }^{51-53,54}$ Taking into account the well probed observation about the active participation of phospholipids in amyloid fibrillogenesis, our experimental evidences are giving strong biophysical support to the active role of organized phospholipids in the formation of irreversible fibril-like structures in a membrane environment.

\section{CONCLUSIONS}

Nano-organized liquid-expanded POPC in lipid monolayers triggers the fibril-like formation structures of $A \beta(1-40)$ peptide at the interface at low peptide area proportion. BAM imaging clearly showed protruding fibril structures that are ThT positive and were well visualized by AFM when the nanoarrangements is transferred to mica support. On the contrary, when the partner lipid of $A \beta(1-40)$ peptide at the surface was the solid DSPC, amyloid peptide keeps its two-dimensional array and its immiscible lateral behaviour without forming amyloid fibrils. The amyloid fibrillation at the interface can be dynamically modulated by the quality of the lipid phase environment, the protein area proportion and the lateral packing. 


\section{EXPERIMENTAL SECTION}

Reagents. $\mathrm{A} \beta(1-40)\left(\mathrm{D}^{1} \mathrm{AEFRHDSGYEVHHQKLVFFAEDVG}{ }^{25} \mathrm{SNKGAIIGLM}^{35} \mathrm{VGGVV}^{40}\right)$, were purchased from Bachem AG (www.bachem.com). The subphase was NaCl $145 \mathrm{mM}$. Water was obtained from a MilliQ system (Millipore, USA) with a conductivity less than $0.085 \mu{\mathrm{S} . \mathrm{cm}^{-1}}^{-1}$ and a surface tension of $72 \mathrm{mN} \cdot \mathrm{m}^{-1} . \mathrm{NaCl}$ from Merck (Gottingen, Germany) was roasted in an appropriate oven at $400-450{ }^{\circ} \mathrm{C}$ for at least 4 hours to eliminate small amount surfactants impurities. POPC (1-pamitoyl-2-oleoylphosphatidylcholine) and DSPC (1,2-disteraoyl-phosphatidylcholine) were purchased from Avanti Polar Lipids, USA. DMSO and Chloroform were from Merck, Göttingen, Germany.

Peptide and lipid monolayers formation and compression $\pi$-Area isotherms. Langmuir monolayers experiments were performed at $23 \pm 0.5^{\circ} \mathrm{C}$. The Langmuir monolayers room was kept at constant temperature with the help of a continuous working individual roof-top air conditioning. Peptide monolayers were formed using a $180 \mathrm{~mL}$ volume Langmuir trough. The subphase was unbuffered $\mathrm{NaCl} 145 \mathrm{mM}, \mathrm{pH}$ 5.6. All the settings were described previously. ${ }^{17-18} \mathrm{~A} \beta$ peptide and lipids were dissolved in pure DMSO and chloroform, respectively, into stock solutions of about $10 \mathrm{mM}$. Individual diluted working solutions were freshly prepared to $\sim 1 \mu \mathrm{M}$. Phospholipids were dissolved in pure chloroform and $\mathrm{A} \beta(1-40)$ in pure DMSO. For mixed monolayers, peptide and lipids were premixed in solution at the desired proportion just before to perform the experiment. $15-30 \mu 1$ of solution was directly spread onto the subphase interface. Surface pressure was determined with a Pt plate using the Wilhelmy method. The continuous symmetric compression was through the automatic simultaneous movement of both barriers that confine the film. The total film area were continuously recorded using trough and software provided by KSV Instruments ${ }^{\circledR}$ Ltd. The usual compression rate used was adjusted at $10 \mathrm{~mm}^{2} \cdot \mathrm{min}^{-1}$, lower barrier speeds were also checked without altering the results. Monolayers formed by pure proteins of their mixtures with lipids usually have slow collapsing transition process giving a non-abruptly discontinuity in the $\pi$-Area isotherms even at the slower compression speed. For this reason, we shown as collapsing point or transition pressure of all isotherms showed in Fig. 2 is the first discontinuity taken from the second derivative of the $\pi$-Area isotherm (Fig. S2). These mathematically calculated values are lower than the first discontinuities observable at first sight in $\pi$-Area isotherms in Fig. 1. Before compression the spread films were allowed to 
equilibrated by 2-3 minutes. Mean Molecular Area (MMA) or the average experimental area per molecule is the available surface area divided by the amount of spread molecules at the interface, according to: $M M A=\left(A_{S} / n_{L}+n_{P}\right)$, where $A_{S}$ is the total available surface area of the trough and $n$ is the amount of lipid $n_{L}$ or protein $n_{P}$ molecules or their mixtures $n_{L}+n_{P}$ spread onto $A_{s}$. $A_{s}$ is automatically calculated by the appropriate software that takes into account the barrier speed and the size of the available surface trough area upon compression. $A_{\text {ideal }}$ is proportional to mole fraction and individual molecular area of the pure components of the mixed monolayer at a defined surface pressure $\pi$ according to $A_{\text {ideal }}=\left(A_{L} X_{L}+A_{P} X_{P}\right)_{\pi}$, where $A_{L}$ and $A_{P}$ are the individual molecular areas and $X_{L}$ and $X_{P}$ the mole fractions of pure lipid and protein, respectively. $M M A$ is the average of at least $4 / 5$ independent determinations with its corresponding standard deviation. The behavior of mixed lipid/peptide monolayers was analyzed by comparing the experimental curves (MMA vs. $\pi$ ) with the theoretical isotherms (Aideal vs. $\pi$ ) for the corresponding films in which no interactions between the molecules are assumed. In a non-interacting behavior, $M M A$ value tends to be close to $\mathrm{A}_{\text {ideal }}$ (ideal mixing behavior). ${ }^{20-21}$ Also, the miscible/immiscible of the mixed interface was determined according to the surface phase rule. ${ }^{21}$

Brewster Angle Microscopy. Monolayers were spread over a Langmuir film balance, as described above, and the films were directly observed along all $\pi$-Area isotherm using a Brewster Angle Microscope (BAM) coupled to an EP3 Imaging Ellipsometer equipment (Accurion, Göttingen, Germany) with a 20x objective (Nikon, Japan, NA 0.35). For each imaging acquisition, the monolayer was compressed by forward compression steps of $5 \mathrm{mN} . \mathrm{m}^{-1}$. During imaging acquisition ( 5 to $20 \mathrm{~s}$ ) the lateral pressure did not exhibit any detectable variation. Three to five images were sequentially taken for each surface pressure, in order to have pictures of different regions of a same monolayer. Results obtained with BAM were compared with the images obtained by using Atomic Force Microscopy (AFM) and Fluorescence Microscopy (FM). Transferred experiments for AFM and FM. Compressed monolayers up to a desired surface pressure were transferred to mica support (Nano-Tec V-1 grade Muscovite of $10 \mathrm{~mm}$ diameter and 0.15-0.21 mm thickness, from Innovative Microscopy Suppliers, Argentina); the mica support is packed in several layers which were used by removing one layer per experiment. The mica face was rinsed with distilled water before transferring the surface material. Langmuir monolayers was then transferred to the support by 
dipping the mica, oriented perpendicular to the trough previously submerged, at the smallest speed (1 $\mathrm{mm} \cdot \mathrm{min}^{-1}$ ) and keeping the surface pressure constant with a surface barostat couple to the barriers of the Langmuir trough. Previous to the transfer, the monolayer was allowed to stabilize ( $\sim 2 \mathrm{~min})$, before being transferred. Each monolayer of either pure components or their mixtures was first compressed up to 20 $\mathrm{mN} . \mathrm{m}^{-1}$ before transferring to mica support.

Fluorescence Microscopy and imaging analysis. The fibril-like structures were visualized by FM by adding a drop of aqueous freshly prepared $10 \mu \mathrm{M}$ ThT probe to the transferred monolayer onto mica support and leave to dry off for 5 minutes. Excitation wavelength was selected with a cutting filter of 450 $\mathrm{nm}$ and the emission taken at $482 \mathrm{~nm}$. Negative controls were done: pure ThT, pure lipid and pure A $\beta$ peptide were subjected to the same procedure (Fig. 4B). As positive control we tested preformed fibrils of $\alpha$-synuclein formed in bulk condition according to Gallea and co-workers ${ }^{55}$ and treated in the same way with ThT by using glass coverslip (Fig. 4B). The images were acquired with an Axioplan Carl Zeiss (Germany) fluorescence microscope equipped with an Olympus video camera (USA). We used a 20x and 40x objectives. The imaging processing and analysis was carried out using both Fiji and Pixinsight v. 1.8.6 software. Both programs allowed us to use some filters and 2D FFT to improve imaging resolution.

Atomic Force Microscopy. AFM measurements were performed on a multimode atomic force microscope SPM, Agilent Technology 5500, USA. We used the mica support as describe above. It was used in contactmode scanning to measure the transferred Langmuir monolayers of $A \beta(1-40)$ peptide/lipid mixed monolayers and their respective controls (pure POPC and pure $\mathrm{A} \beta(1-40)$ peptide). All the experiments were carried out at room temperature. Resolution images of $512 \times 512$ pixels were collected at a scanning rate in between 0.3 and $0.4 \mathrm{ln} \cdot \mathrm{sec}^{-1}$. The height and error-signal (vertical deflection), friction and topography images were taken simultaneously.

\section{ASSOCIATED CONTENT \\ Supporting information \\ Supplementary figures are provided. \\ AUTHOR INFORMATION}


$\mathrm{ABA}$ and $\mathrm{BC}$ have contributed equally to this work as co-first authors.

\section{Corresponding author}

gfidelio@unc.edu.ar

\section{Notes}

The authors declare no competing financial interest.

\section{ACKNOWLEDGEMENTS}

This work was supported, in part, by grants from MinCyT Córdoba, CONICET, FONCYT (PICT 2016-1010) and SeCyT-UNC, Argentina. A.B.A. is doctoral fellow from CONICET. G.D.F and B.C. are members of the Scientific National Research Career (CIC) of CONICET, Argentina. P.E.A.R. is a researcher from Ministerio de Ciencia y Tecnología de la Provincia de Córdoba, Argentina. P.E.A.R. and G.D.F give special thanks to TRB Pharma SA (Buenos Aires, Argentina) and TRB Chemedica International (Genève, Switzerland) for the generous gift of $A \beta(1-40)$ peptide and by its interest to finance us the research of the effect of different lipids on amyloid fibrillation. S.B.P is Emeritus Professor at the Department of Health Science and Technology, Faculty of Medicine, Aalborg University, Denmark. All microscopes used in this work belong to the "Centro de Microscopía Óptica y Confocal Avanzada de Córdoba" (CEMINCO), integrated to the "Sistema Nacional de Microscopía (SNM-MINCyT), Argentina. The authors thank Dr. M.S. Celej for the gift of recombinant $\alpha$-synuclein for ThT staining experiments.

\section{REFERENCES}

1. Selkoe, D. J.; Hardy, J., The amyloid hypothesis of Alzheimer's disease at 25 years. EMBO molecular medicine 2016, 8 (6), 595-608.

2. Williamson, R.; Sutherland, C., Neuronal membranes are key to the pathogenesis of Alzheimer's disease: the role of both raft and non-raft membrane domains. Current Alzheimer research 2011, 8 (2), 213-21.

3. Thinakaran, G.; Koo, E. H., Amyloid precursor protein trafficking, processing, and function. $J$ Biol Chem 2008, 283 (44), 29615-9.

4. Tiwari, S.; Atluri, V.; Kaushik, A.; Yndart, A.; Nair, M., Alzheimer's disease: pathogenesis, diagnostics, and therapeutics. International journal of nanomedicine 2019, 14, 5541-5554.

5. Goni, F. M., "Rafts": A nickname for putative transient nanodomains. Chem Phys Lipids 2019, 218, 34-39.

6. Fabiani, C.; Antollini, S. S., Alzheimer's Disease as a Membrane Disorder: Spatial Cross-Talk Among BetaAmyloid Peptides, Nicotinic Acetylcholine Receptors and Lipid Rafts. Frontiers in cellular neuroscience 2019, 13, 309.

7. Kosicek, M.; Hecimovic, S., Phospholipids and Alzheimer's disease: alterations, mechanisms and potential biomarkers. International journal of molecular sciences 2013, 14 (1), 1310-22.

8. $\quad$ Oshima, N.; Morishima-Kawashima, M.; Yamaguchi, H.; Yoshimura, M.; Sugihara, S.; Khan, K.; Games, D.; Schenk, D.; Ihara, Y., Accumulation of amyloid beta-protein in the low-density membrane domain accurately reflects the extent of beta-amyloid deposition in the brain. The American journal of pathology 2001, 158 (6), 2209-18.

9. Choi, J.; Yin, T.; Shinozaki, K.; Lampe, J. W.; Stevens, J. F.; Becker, L. B.; Kim, J., Comprehensive analysis of phospholipids in the brain, heart, kidney, and liver: brain phospholipids are least enriched with polyunsaturated fatty acids. Molecular and cellular biochemistry 2018, 442 (1-2), 187-201. 
10. Farooqui, A. A.; Liss, L.; Horrocks, L. A., Neurochemical aspects of Alzheimer's disease: involvement of membrane phospholipids. Metabolic brain disease 1988, 3 (1), 19-35.

11. Nitsch, R. M.; Blusztajn, J. K.; Pittas, A. G.; Slack, B. E.; Growdon, J. H.; Wurtman, R. J., Evidence for a membrane defect in Alzheimer disease brain. Proc Natl Acad Sci U S A 1992, 89 (5), 1671-5.

12. Guan, Z.; Wang, Y.; Cairns, N. J.; Lantos, P. L.; Dallner, G.; Sindelar, P. J., Decrease and structural modifications of phosphatidylethanolamine plasmalogen in the brain with Alzheimer disease. Journal of neuropathology and experimental neurology 1999, 58 (7), 740-7.

13. Mulder, C.; Wahlund, L. O.; Teerlink, T.; Blomberg, M.; Veerhuis, R.; van Kamp, G. J.; Scheltens, P.; Scheffer, P. G., Decreased lysophosphatidylcholine/phosphatidylcholine ratio in cerebrospinal fluid in Alzheimer's disease. Journal of neural transmission 2003, 110 (8), 949-55.

14. Del Mar Martinez-Senac, M.; Villalain, J.; Gomez-Fernandez, J. C., Structure of the Alzheimer beta-amyloid peptide (25-35) and its interaction with negatively charged phospholipid vesicles. Eur J Biochem 1999, 265 (2), 74453.

15. Vander Zanden, C. M.; Wampler, L.; Bowers, I.; Watkins, E. B.; Majewski, J.; Chi, E. Y., Fibrillar and Nonfibrillar Amyloid Beta Structures Drive Two Modes of Membrane-Mediated Toxicity. Langmuir 2019, 35 (48), 16024-16036.

16. Thakur, G.; Micic, M.; Leblanc, R. M., Surface chemistry of Alzheimer's disease: a Langmuir monolayer approach. Colloids and surfaces. B, Biointerfaces 2009, 74 (2), 436-56.

17. Ambroggio, E. E.; Kim, D. H.; Separovic, F.; Barrow, C. J.; Barnham, K. J.; Bagatolli, L. A.; Fidelio, G. D., Surface behavior and lipid interaction of Alzheimer beta-amyloid peptide 1-42: a membrane-disrupting peptide. Biophys J 2005, 88 (4), 2706-13.

18. Caruso, B.; Ambroggio, E. E.; Wilke, N.; Fidelio, G. D., The rheological properties of beta amyloid Langmuir monolayers: Comparative studies with melittin peptide. Colloids and surfaces. B, Biointerfaces 2016, 146, 180-7.

19. Benarouche, A.; Habchi, J.; Cagna, A.; Maniti, O.; Girard-Egrot, A.; Cavalier, J. F.; Longhi, S.; Carriere, F., Interfacial Properties of NTAIL, an Intrinsically Disordered Protein. Biophys J 2017, 113 (12), 2723-2735.

20. Fidelio, G. D.; Maggio, B.; Cumar, F. A., Interaction of myelin basic protein, melittin and bovine serum albumin with gangliosides, sulphatide and neutral glycosphingolipids in mixed monolayers. Chem Phys Lipids 1984, 35 (3), 231-45.

21. Gaines, G. L., Insoluble monolayers at liquid-gas interfaces. Interscience Publishers: New York, 1966.

22. Jones, M. N., BIOLOGICAL INTERFACES: An Introduction to the Surface and Colloid Science of Biochemical and Biological Systems. ELSELVIER SCIENTIFIC PUBLISHING COMPANY: Amsterdan and New York., 1975.

23. McConnell, H. M.; Tamm, L. K.; Weis, R. M., Periodic structures in lipid monolayer phase transitions. Proc Natl Acad Sci U S A 1984, 81 (10), 3249-53.

24. Losche, M.; Mohwald, H., Impurity controlled phase transitions of phospholipid monolayers. European biophysics journal : EBJ 1984, 11 (1), 35-42.

25. Damodaran, S., Beyond the hydrophobic effect: Critical function of water at biological phase boundaries--A hypothesis. Adv Colloid Interface Sci 2015, 221, 22-33.

26. Fidelio, G. D.; Maggio, B.; Cumar, F. A., Interaction of melittin with glycosphingolipids and phospholipids in mixed monolayers at different temperatures. Effect of the lipid physical state. Biochimica et Biophysica Acta Biomembranes 1986, 862 (1), 49-56.

27. Milner, S. T.; Joanny, J. F.; Pincus, P., Buckling of Langmuir Monolayers. Europhys. Lett. 1989, 9 (5), 495.

28. LeVine, H., 3rd, Thioflavine T interaction with synthetic Alzheimer's disease beta-amyloid peptides: detection of amyloid aggregation in solution. Protein Sci 1993, 2 (3), 404-10.

29. Biancalana, M.; Koide, S., Molecular mechanism of Thioflavin-T binding to amyloid fibrils. Biochim Biophys Acta 2010, 1804 (7), 1405-12.

30. Ban, T.; Hamada, D.; Hasegawa, K.; Naiki, H.; Goto, Y., Direct observation of amyloid fibril growth monitored by thioflavin T fluorescence. J Biol Chem 2003, 278 (19), 16462-5.

31. Sparr, E.; Linse, S., Lipid-protein interactions in amyloid formation. Biochimica et biophysica acta. Proteins and proteomics 2019, 1867 (5), 455-457.

32. Schladitz, C.; Vieira, E. P.; Hermel, H.; Mohwald, H., Amyloid-beta-sheet formation at the air-water interface. Biophys J 1999, 77 (6), 3305-10.

33. Maltseva, E.; Brezesinski, G., Adsorption of amyloid beta (1-40) peptide to phosphatidylethanolamine monolayers. Chemphyschem : a European journal of chemical physics and physical chemistry 2004, 5 (8), 1185-90.

34. Chi, E. Y.; Frey, S. L.; Winans, A.; Lam, K. L.; Kjaer, K.; Majewski, J.; Lee, K. Y., Amyloid-beta fibrillogenesis seeded by interface-induced peptide misfolding and self-assembly. Biophys J 2010, 98 (10), 2299-308. 
35. Jiang, D.; Dinh, K. L.; Ruthenburg, T. C.; Zhang, Y.; Su, L.; Land, D. P.; Zhou, F., A kinetic model for beta-amyloid adsorption at the air/solution interface and its implication to the beta-amyloid aggregation process. J Phys Chem $B$ 2009, $113(10), 3160-8$.

36. Jiang, D.; Rauda, I.; Han, S.; Chen, S.; Zhou, F., Aggregation pathways of the amyloid beta(1-42) peptide depend on its colloidal stability and ordered beta-sheet stacking. Langmuir 2012, 28 (35), 12711-21.

37. Ambroggio, E. E.; Fidelio, G. D., Lipid-like behavior of signal sequence peptides at air-water interface. Biochim Biophys Acta 2013, 1828 (2), 708-14.

38. Pressl, K.; Jorgensen, K.; Laggner, P., Characterization of the sub-main-transition in distearoylphosphatidylcholine studied by simultaneous small- and wide-angle X-ray diffraction. Biochim Biophys Acta 1997, 1325 (1), 1-7.

39. Prenner, E.; Honsek, G.; Honig, D.; Mobius, D.; Lohner, K., Imaging of the domain organization in sphingomyelin and phosphatidylcholine monolayers. Chem Phys Lipids 2007, 145 (2), 106-18.

40. Fidorra, M.; Duelund, L.; Leidy, C.; Simonsen, A. C.; Bagatolli, L. A., Absence of fluid-ordered/fluid-disordered phase coexistence in ceramide/POPC mixtures containing cholesterol. Biophys J 2006, 90 (12), 4437-51.

41. Brewer, J.; de la Serna, J. B.; Wagner, K.; Bagatolli, L. A., Multiphoton excitation fluorescence microscopy in planar membrane systems. Biochim Biophys Acta 2010, 1798, 1301-1308.

42. Morinaga, A.; Hasegawa, K.; Nomura, R.; Ookoshi, T.; Ozawa, D.; Goto, Y.; Yamada, M.; Naiki, H., Critical role of interfaces and agitation on the nucleation of Abeta amyloid fibrils at low concentrations of Abeta monomers. Biochim Biophys Acta 2010, 1804 (4), 986-95.

43. Campioni, S.; Carret, G.; Jordens, S.; Nicoud, L.; Mezzenga, R.; Riek, R., The presence of an air-water interface affects formation and elongation of alpha-Synuclein fibrils. J Am Chem Soc 2014, 136 (7), 2866-75.

44. Terzi, E.; Holzemann, G.; Seelig, J., Interaction of Alzheimer beta-amyloid peptide(1-40) with lipid membranes. Biochemistry 1997, 36 (48), 14845-52.

45. Hertel, C.; Terzi, E.; Hauser, N.; Jakob-Rotne, R.; Seelig, J.; Kemp, J. A., Inhibition of the electrostatic interaction between beta-amyloid peptide and membranes prevents beta-amyloid-induced toxicity. Proc Natl Acad Sci U S A 1997, 94 (17), 9412-6.

46. Fischer, H.; Polikarpov, I.; Craievich, A. F., Average protein density is a molecular-weight-dependent function. Protein Sci 2004, 13 (10), 2825-8.

47. Ahyayauch, H.; Raab, M.; Busto, J. V.; Andraka, N.; Arrondo, J. L.; Masserini, M.; Tvaroska, I.; Goni, F. M., Binding of beta-amyloid (1-42) peptide to negatively charged phospholipid membranes in the liquid-ordered state: modeling and experimental studies. Biophys J 2012, 103 (3), 453-63.

48. Sparr, E.; Engel, M. F.; Sakharov, D. V.; Sprong, M.; Jacobs, J.; de Kruijff, B.; Hoppener, J. W.; Killian, J. A., Islet amyloid polypeptide-induced membrane leakage involves uptake of lipids by forming amyloid fibers. FEBS Lett 2004, $577(1-2), 117-20$.

49. Domanov, Y. A.; Kinnunen, P. K., Islet amyloid polypeptide forms rigid lipid-protein amyloid fibrils on supported phospholipid bilayers. J Mol Biol 2008, 376 (1), 42-54.

50. Hellstrand, E.; Grey, M.; Ainalem, M. L.; Ankner, J.; Forsyth, V. T.; Fragneto, G.; Haertlein, M.; Dauvergne, M. T.; Nilsson, H.; Brundin, P.; Linse, S.; Nylander, T.; Sparr, E., Adsorption of alpha-synuclein to supported lipid bilayers: positioning and role of electrostatics. ACS chemical neuroscience 2013, 4 (10), 1339-51.

51. Kaya, I.; Brinet, D.; Michno, W.; Baskurt, M.; Zetterberg, H.; Blenow, K.; Hanrieder, J., Novel Trimodal MALDI Imaging Mass Spectrometry (IMS3) at 10 mum Reveals Spatial Lipid and Peptide Correlates Implicated in Abeta Plaque Pathology in Alzheimer's Disease. ACS chemical neuroscience 2017, 8 (12), 2778-2790.

52. Gellermann, G. P.; Appel, T. R.; Tannert, A.; Radestock, A.; Hortschansky, P.; Schroeckh, V.; Leisner, C.; Lutkepohl, T.; Shtrasburg, S.; Rocken, C.; Pras, M.; Linke, R. P.; Diekmann, S.; Fandrich, M., Raft lipids as common components of human extracellular amyloid fibrils. Proc Natl Acad Sci U S A 2005, 102 (18), 6297-302.

53. Kiskis, J.; Fink, H.; Nyberg, L.; Thyr, J.; Li, J. Y.; Enejder, A., Plaque-associated lipids in Alzheimer's diseased brain tissue visualized by nonlinear microscopy. Scientific reports 2015, 5, 13489.

54. Halliday, G. M.; Ophof, A.; Broe, M.; Jensen, P. H.; Kettle, E.; Fedorow, H.; Cartwright, M. I.; Griffiths, F. M.; Shepherd, C. E.; Double, K. L., Alpha-synuclein redistributes to neuromelanin lipid in the substantia nigra early in Parkinson's disease. Brain : a journal of neurology 2005, 128 (Pt 11), 2654-64.

55. Gallea, J. I.; Sarroukh, R.; Yunes-Quartino, P.; Ruysschaert, J. M.; Raussens, V.; Celej, M. S., Structural remodeling during amyloidogenesis of physiological Nalpha-acetylated alpha-synuclein. Biochim Biophys Acta 2016, 1864 (5), 501-10. 


\section{TOC graphic}

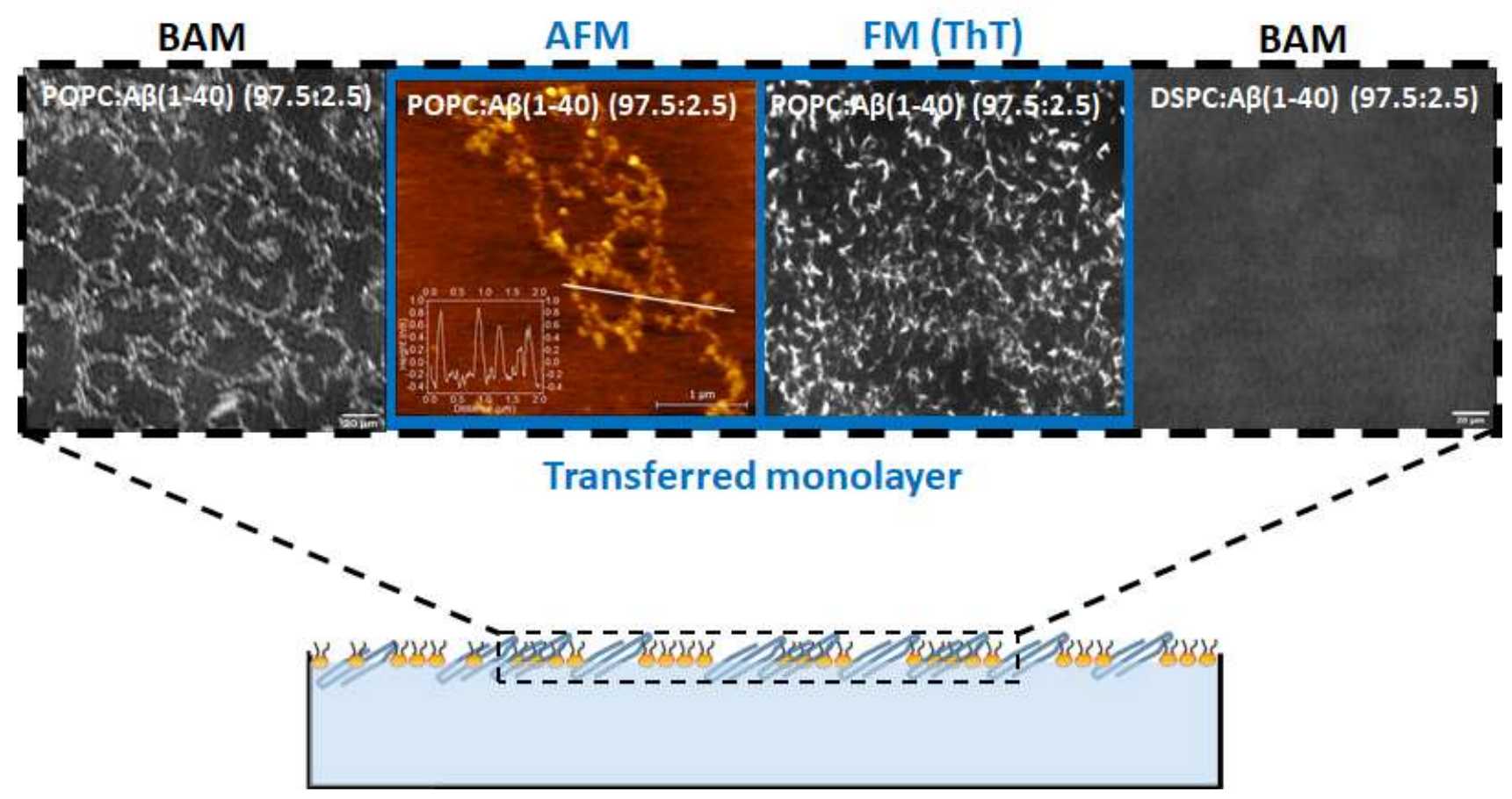

